\title{
ANALOGÍAS Y DIVERGENCIAS DE LA SIMBOLOGÍA LABERÍNTICA ENTRE CINE Y VIDEOJUEGOS
}

\author{
Fran MATEU \\ Universidad de Alicante
}

\section{RESUMEN}

El laberinto, como símbolo o figura retórica, se enmarca en un estado de realidad conectado con la iniciación y saber encontrar el camino de uno mismo. Es un arquetipo cuyo carácter simbólico recae sobre ese símil con la vida, encerrándose en sí mismo y vinculándose con el nacimiento y la muerte, adoptando esa simbología que revela los aspectos más profundos de la realidad. En este contexto simbólico, el laberinto tiene presencia e influencias a diferentes niveles que se revisan en el texto, con algunos ejemplos de la industria cultural que parten de novelas como Alice's Adventures in Wonderland, The Shining o II nome della rosa, pero su adaptación entre cine y videojuegos lo proyecta mental y espacialmente de diferentes formas, divergiendo el lenguaje audiovisual del lenguaje del videojuego, donde el laberinto se ha convertido en un género en sí mismo.

Palabras clave: laberinto, símbolo, cine, videojuegos, industria cultural.

\section{ABSTRACT}

The labyrinth, as a symbol or rhetorical figure, is framed in a state of reality connected with initiation and to know how to find the path of oneself. It's an archetype whose symbolic character rests on that simile with life, closing in on itself and connected with birth and death, adopting that symbolism that reveals the deeper aspects of reality. In this symbolic context, the labyrinth has presence and influences at different levels that are reviewed in the text, with some examples from cultural industry that began from novels like Alice's Adventures in Wonderland, The Shining or II nome della rosa, but its adaptation between cinema and video games is projected mentally and spatially by different ways, diverging the audiovisual language from the video game language, where the labyrinth has become a genre in itself.

Keywords: labyrinth, symbol, cinema, video games, cultural industry. 


\section{INTRODUCCIÓN}

La simbología laberíntica manifiesta una analogía con la iniciación, el movimiento y las etapas de la vida, produciendo un gran impacto en la configuración de arquetipos vinculados a la búsqueda y el aprendizaje para hallar una salida, un objetivo. El laberinto posee diferentes definiciones, aunque la española más antigua se le atribuye a Sebastián de Covarrubias'. No obstante, su definición siempre está vinculada al deseo del laberinto, como ente simbólico, de poner dificultades o pruebas a aquellos que se adentran en él, de modo que no encuentren la salida con facilidad, hallándose ante bifurcaciones con situaciones de confusión y perplejidad. Sin embargo, el laberinto se crea siempre bajo una misma premisa, que difiere del hecho de que la persona que se adentre en él se extravíe o no logre hallar la salida.

El discurso y símbolo laberíntico, extrapolado a un nivel espacial y mental, se crea con el objetivo de que se pueda resolver. Por mucha confusión, misterio o conflicto que exista en él, siempre habrá una solución que será inherente a la dificultad planteada desde el principio. Tanto en el cine como en los videojuegos (que contengan discursos laberínticos), los personajes ${ }^{2}$ serán potencialmente capaces de resolver o sortear dificultades hasta llegar al objetivo final.

En consecuencia, el laberinto como elemento espacial (físico o virtual) o mental siempre será afrontado en base a un objetivo que se debe cumplir. El símbolo laberintico, además de oculto y complejo, también es ambiguo, ya que está conectado a un carácter lúdico, vinculado irremediablemente a los videojuegos. Prevalece el inconsciente deseo inicial de adentrarse en ese mundo o microcosmos, junto al placer de alcanzar el objetivo final. Ese logro está conectado al hallazgo de la intrincada salida de uno mismo y del propio reencuentro, relacionándose a su vez con la muerte y el renacimiento, siendo un factor análogo al discurso del videojuego, pues sólo se puede avanzar hacia el objetivo final, y no caer en la muerte o el renacimiento ${ }^{3}$, gracias a la correcta toma de decisiones y a través de la experiencia.

Además, el proceso de descubrir la salida o lograr el objetivo final sólo es posible a través de una actitud dinámica. En este sentido, no se puede superar un laberinto huyendo de su propia dificultad. Este factor se debe a que existe un recorrido que hay que afrontar en un lugar creado artificialmente con sus propias reglas, accediendo primero a ese espacio para después madurar e iluminarse en él (en un carácter más iniciático), volviendo a la realidad una vez superado.

El laberinto, además de ser uno de los símbolos arquitectónicos más antiguos, se haya presente en numerosos jardines y templos a nivel geográfico (Fig. 1). Se trata de un elemento que forma parte del subconsciente colectivo $y$, en consecuencia, está muy arraigado en nuestra cultura (Santarcangeli, 1997). Ha sido representado prácticamente en todas las culturas, además de formar parte del folclore, los mitos y las leyendas afines a esas sociedades, como es el caso de la antigua fábula griega del laberinto construido

1 Sebastián de Covarrubias y Orozco definió el laberinto como «un lugar de muchas vías con sinuosidades cambiantes» (De Covarrubias, 1943:746).

2 Se empleará el término «personajes» para aludir al mismo tiempo a seres humanos o de cualquier otra naturaleza que han sido creados dentro de un discurso ficticio con el fin de generar una catarsis con el espectador o el jugador.

3 Morir en un videojuego implica volver a empezar la partida desde un determinado lugar, ofreciéndose ese carácter extradiegético de renacimiento. No obstante, existen videojuegos en los que al morir se disipa todo lo avanzado y hay que comenzar desde el principio; e incluso videojuegos en los que si se muere, no se pueden volver a jugar, como sucede en Upsilon Circuit (2016), desarrollado por Robot Loves Kitty. 
por Dédalo para retener al Minotauro (Graves, 1988), adaptada posteriormente por un elevado número de autores ${ }^{4}$ ofreciendo nuevos puntos de vista. Esas leyendas se han vuelto a adaptar con nuevos enfoques o reinterpretaciones, generando a su vez nuevas obras literarias y trasladándose a los nuevos soportes de la industria cultural, como el cine o los videojuegos ${ }^{5}$. Son historias en las que siempre hay que afrontar un camino de precisa geometría y estructura, pero engañoso por sus diversas posibilidades, transfiguraciones espaciales (convirtiéndose en un ente cambiante) y similitudes, como sucedería con un frondoso bosque de monótonos árboles ${ }^{6}$.

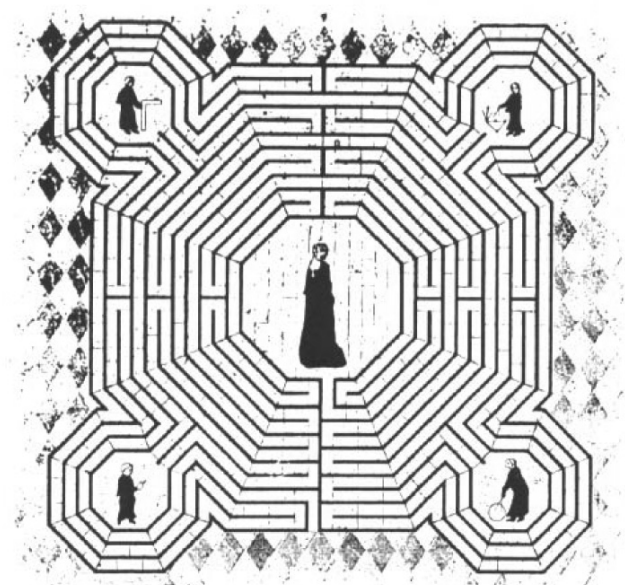

Figura 1: Grabado del laberinto de la Catedral de Reims (1286).

Fuente: <https://sildavia9.wordpress.com/category/mitologia/page/2/>

[consulta: 5 mayo 2017].

\section{ANALOGÍAS Y DIVERGENCIAS DE LA SIMBOLOGÍA LABERÍNTICA}

El lenguaje audiovisual y el lenguaje del videojuego utilizan diferentes códigos, aunque los videojuegos han experimentado una evolución hacia un soporte cada vez más cinematográfico frente al estatismo del propio cine en cuanto a la forma de ofrecer la obra fílmica al espectador. Salvo casos muy excepcionales a mediados del siglo $X X^{7}$, el cine no ha generado una

4 Jorge Luis Borges, por ejemplo, escribió La casa de Asterión, un cuento corto publicado dentro de El Aleph (1949). Es una historia sobre la soledad construida a través de un monólogo del propio Minotauro. Otro ejemplo es el de Nikos Kazantzakis, escritor que recreó en la obra teatral Teseo (1958) la lucha de éste contra el Minotauro en una versión que simbolizaba el enfrentamiento del ser humano contra Dios, representado en la civilización cretense a través del toro.

5 Por ejemplo, el largometraje Teseo contro il minotauro (1960), de Silvio Amadio; el cortometraje de animación The Labyrinth (1971), de Alexandra Snezhko-Blotskaya; la saga de videojuegos God of War, iniciada en 2015 por SCE Santa Monica Studio; o el videojuego The Minotaur (2016), desarrollado por Ratalaika Games.

6 El héroe del folclore inglés Robin Hood hizo uso, junto al resto de proscritos, del bosque de Sherwood para esconderse en él gracias a la dificultad de ser encontrados allí, utilizando el espacio del monótono bosque bajo un paradigma laberíntico. Otro ejemplo se halla en Blair Witch Project (1999), película dirigida por Eduardo Sánchez y Daniel Myrick, cuyos protagonistas se pierden en el bosque a causa de los árboles, que parecen repetirse constantemente, siendo una obra que ha inspirado posteriormente a otros trabajos, como el videojuego Slender: The Arrival (2013), desarrollado por Blue Isle Studios.

7 El cineasta estadounidense William Castle convirtió el gimmick, o discurso inaugural, como parte de su obra, advirtiendo al público de lo que iban a ver. Cuando rodó Macabre (1958), se anunció a los espectadores que al comprar la entrada estaban asegurados con una póliza de mil dólares en caso de muerte. A pesar de 
interactividad real hasta bien entrado el siglo XXI, como es el caso de Last Call (2010), largometraje dirigido por Grady Weatherford y producido por 13th Street, siendo una película interactiva a través del teléfono móvil (Herrero, 2015: 180). Los nuevos formatos y su interactividad están haciendo que la frontera entre cine y videojuegos esté cada vez menos presente.

El lenguaje cinematográfico (en parámetros de simbología laberíntica), y el de los videojuegos desarrollados bajo los mismos códigos audiovisuales, se basa en la narrativa del propio plano, donde se activan los valores del dentro o fuera de campo y el movimiento de cámara desde el punto de vista subjetivo del propio personaje, sobre todo en largos planos secuencia, generándose dos analogías básicas entre ambos soportes de la industria cultural. Existen obras audiovisuales rodadas en su totalidad desde el punto de vista subjetivo de un personaje, como el largometraje ruso Hardcore Henry (2015), de Ilya Naishuller, que se vendió como la primera película de acción rodada íntegramente en primera persona (Peckham, 2016), aunque Lady in the Lake (1947), de Robert Montgomery, se adelantó mucho antes $^{8}$. A pesar de que en ambos ejemplos hay una simbología laberíntica (a nivel mental y espacial), el punto de vista subjetivo en el cine no debería acuñarse necesariamente como una decisión estilística heredada de la narrativa de los videojuegos en primera persona, los cuales se iniciaron desde una perspectiva cenital (Donovan, 2010). No obstante, existen casos de videojuegos que han sido adaptados al ámbito cinematográfico recreando en primera persona alguna de sus escenas para captar mejor la esencia del propio videojuego, como es el caso de Doom (2005), dirigida por Andrzej Bartkowiak, o House of the Dead (2003), dirigida por Uwe Boll, en la que directamente se construyen escenas en primera persona que parecen proceder del propio videojuego.

Respecto al dentro y fuera de campo, esta propiedad conecta al espectador con el suspense de lo que no se ve (y se sugiere) y al laberinto en sí mismo, basándose en la fórmula de retener información, dosificando la manera en la que ésta se ofrece al público e incluso a los propios personajes. Se trata de una analogía fundamental entre cine y videojuegos. Este factor genera una falta de visión, conociendo únicamente lo que hay delante (dentro de campo), originándose una dualidad del espacio laberíntico aplicada al dentro y fuera de campo. Por un lado, por su carácter de espacio infinito, y por otro, por su carácter carcelario", como si se estuviese atrapado sin salida (Bonitzer, 1981: 56-63). Se proyecta bajo una visión bloqueada y restringida por el fuera de campo, pero asumiendo que existe algo más allá

que la obra carecía del gran poder terrorífico que se sugería en el seguro de vida, esta treta publicitaria hizo de Macabre un éxito comercial. Posteriormente, Castle hizo House on Haunted Hill (1959), y promocionó la película argumentando que ésta tenía un innovador efecto especial (efecto emergo) que se basaba en lograr que los fantasmas de la película salieran de la pantalla. Otro ejemplo de su trabajo interactivo fue en Mr. Sardonicus (1961), obra en la que se realizaba un supuesto juego de interactividad: a mitad del metraje, Castle aparecía en la pantalla y pedía a los espectadores que subieran o bajaran el pulgar mediante un cartel para decidir el destino del enemigo, y el público procedía a cumplir con su petición mientras que él (supuestamente) contaba los votos, reflejando siempre el mismo resultado (Castle, 1976).

8 Se utilizó la cámara subjetiva durante toda la película, como si el público viera lo mismo que el detective Philip Marlowe. Ese mismo año, el director Delmer Daves usó la misma técnica durante tres cuartos de hora en su largometraje Dark Passage (1947). Otros ejemplos emblemáticos más recientes en los que se recrean escenas concretas mediante esta técnica ( $\sin$ incluir la cámara en mano o el found footage) son The Terminator (1984), de James Cameron; RoboCop (1987), de Paul Verhoeven; Russian Ark (2002), de Alexander Sokurov; Le scaphandre et le papillon (2007), de Julian Schnabel; Enter the Void (2009), de Gaspar Noé; o Maniac (2012), de Franck Khalfoun, siendo una adaptación del clásico slasher de William Lusting.

9 El carácter carcelario que propone Bonitzer conecta directamente con Dante, Piranesi, Escher y otros autores que se citarán posteriormente en el texto. 
que se podría extender constantemente. En este aspecto, el laberinto sería una cárcel sin límites, sobre todo dentro del género del thriller con historias detectivescas de argumentos laberínticos en cuanto a su estructura, como el ya citado largometraje Lady in the Lake (1947) o The Third Man (1949), dirigido por Carol Reed y escrito por Graham Greene, en el que las cloacas de Viena funcionan como un laberinto de oscuros recovecos muy parecidos entre sí.

Por otro lado, la narrativa del videojuego, a diferencia del discurso cinematográfico clásico, crea y perfila su personaje a través del jugador gracias a un entorno de interactividad e inmersión, haciéndole seguir un camino dentro de las bifurcaciones laberínticas, abriendo puertas, cerrando otras, traspasando umbrales, resolviendo acertijos, etc. Gracias a la propia interfaz del videojuego, la experiencia interactiva hace partícipe al espectador, que se convierte en jugador. En consecuencia, el desafío y el misterio que propone el laberinto es la aventura en sí misma de adentrarse en él (Freire, 2009). Se produce esa empatía en la que el jugador es el propio personaje del videojuego. En este aspecto, el cine (en su discurso más clásico no interactivo o inmersivo) limita a los espectadores a un rol de voyeurs, pudiendo conectar emocionalmente con los personajes de la obra cinematográfica, pero sin ser partícipes activos del discurso. Cuando el cine interactivo se estandarice como un producto de consumo habitual, las fronteras entre cine y videojuegos se fusionarán aún más, ya que los videojuegos, poco a poco, están alcanzando al discurso cinematográfico, no sólo en su lenguaje, sino también en su propia estrategia de comunicación ${ }^{10}$.

\section{ADAPTACIÓN DE LA SIMBOLOGÍA LABERÍNTICA}

Dentro del discurso cinematográfico es necesario citar algunos títulos no mencionados anteriormente cuya simbología laberíntica es latente, como sería el caso del largometraje Spellbound (1945), de Aldred Hitchcock, en el que el laberinto mental que padece el Dr. Edwardes, cuyas imágenes oníricas para la película fueron ilustradas por Salvador Dalí (Truffaut, 1974: 138) es tratado por la Dra. Constance Petersen. El largometraje es una adaptación de la novela The House of Dr. Edwardes (1927), escrita por Francis Beeding, y con el mismo título existen diversos videojuegos, aunque carecen de relación temática. Otro ejemplo, también de Hitchcock, es Psycho (1960) ${ }^{11}$, con guion escrito por Joseph Stefano basándose en la novela homónima de Robert Bloch publicada en 1959. La obra aborda el laberinto mental del personaje de Norman Bates, y en su traslado al videojuego se encuentra Gates Motel (2016), desarrollado por Patagoniart Gaming Studio (Agudo, 2016). En el videojuego se homenajea a la película de Hitchcock y, a su vez, se introduce el laberinto mental de Bates y el del propio motel como espacio desconocido en el que hay que conseguir elementos para poder avanzar.

Otro caso de laberinto mental, también vinculado a los conflictos intrapersonales ${ }^{12}$, se encuentra en el largometraje The Trial (1962), de Orson Welles, en el que el laberinto es

10 Por ejemplo, el tráiler del videojuego Death Stranding (2017), de Kojima Productions, se promocionó en los Game Awards (2016) como el lanzamiento del tráiler de una obra cinematográfica, con caras conocidas de Hollywood (como Guillermo del Toro, Mads Mikkelsen o Norman Reedus) encarnando a los personajes principales.

11 Inspirada, a su vez, en el caso real del asesino en serie Ed Gein (1906-1984), y con posteriores adaptaciones, como la serie Bates Motel (2013).

12 Los conflictos intrapersonales aluden a los conflictos internos de cada persona, y en la ficción estarían conectados a los laberintos mentales, ubicados en las mentes de los personajes. 
la ideología en sí misma, basándose en la novela Der Prozess (1925), de Franz Kafka. Las novelas de Kafka han recreado universos intrigantes y surrealistas, y eco de ello se hizo la desarrolladora de videojuegos Laughing Squid con The Franz Kafka Videogame (2014)13. El videojuego es una adaptación global de las historias de Kafka (no únicamente de The Trial), y es el personaje de $K^{14}$ quien utiliza el jugador para transitar en ese mundo onírico, surrealista e incierto donde se respira esa atmósfera de laberintos mentales.

Convergiendo por nomenclatura también se encuentra el largometraje Kafka (1991), de Steven Soderbergh, cuya trama (lejos de ser un biopic del escritor checo) aborda el laberinto mental de un vendedor de seguros que ingresa en un turbulento colectivo. Otro ejemplo en el que el laberinto mental influye de manera notable se encuentra en la novela Strange Case of Dr. Jekyll and Mr. Hyde (1886), de R. L. Stevenson. La relación entre el bien y el mal del Dr. Henry Jekyll se ha adaptado al cine en multitud de ocasiones ${ }^{15}$. No obstante, la adaptación cinematográfica Dr. Jekyll and Mr. Hyde (1931), dirigida por Rouben Mamoulian, representa una versión imprescindible de la historia de Stevenson. La obra de Mamoulian marca el laberinto mental del personaje dual en una transformación que cuenta con una escena en la que el Dr. Jekyll sufre un mareo tras beberse la poción y, poco a poco, camina hasta el espejo de su laboratorio en el que se observa a sí mismo, viendo cómo se transforma en Edward Hyde. Todo ello mostrado a través del punto de vista subjetivo de la cámara, marcándose la idea de la configuración en primera persona conectada con el laberinto mental del personaje.

El primer traslado a videojuego de la novela de Stevenson tuvo lugar en 1988, cuando Nintendo sacó a la venta Dr. Jekyll and Mr. Hyde. Posteriormente, sin incluir títulos de especial relevancia o con el Dr. Jekyll en un papel secundario, la desarrolladora In Utero presentó en 2001 el videojuego Jekyll \& Hyde (Donovan, 2010). En ambos casos, el personaje transita por historias en las que su laberinto mental está presente. Existen otros ejemplos de laberintos mentales, como el largometraje Memento (2000), de Christopher Nolan, cuyo concepto laberíntico se traslada también a la propia forma, usando además una narrativa invertida análoga a la propia premisa de la historia, en la que el personaje de Leonard Shelby padece la incapacidad amnésica de recordar información más allá de unos minutos. La historia fue escrita por Jonathan Nolan (hermano del director), y actualmente existe un videojuego homónimo que desarrolló Labo Game Studio en 2016 (Ginser, 2016), el cual aborda una historia de terror y aventuras en una enigmática isla. Se trata de un JRPG ${ }^{16}$ con diferentes finales posibles, y mantiene una estructura laberíntica desde una perspectiva cenital. Aunque el videojuego transmite la idea de laberinto mental que también se traslada del fondo a la forma, no se trata de una adaptación del discurso cinematográfico. Vinculado directamente al cine de Nolan, otro título que afronta el laberinto mental es el anime japonés Paprika (2006), de Satoshi Kon, el cual influenció a Nolan ${ }^{17}$ a la hora de realizar Inception (2010),

13 Disponible en The Franz Kafka Videogame (2014); <http://kafkagame.blogspot.com.es/> [consulta: 5 mayo 2017].

14 En Der Prozess, el personaje principal se llama Josef K.; y en The Castle, novela de Kafka publicada en $1926, K$ es el nombre que recibe su protagonista.

15 Por ejemplo, Le testament du Docteur Cordelier (1959), de Jean Renoir; The two faces of Dr. Jekyll (1960), de Terence Fisher; o el musical de Broadway Jekyll and Hyde (1997).

16 JRPG: videojuegos de rol japoneses (Japanese Role-Playing Games).

17 Christopher Nolan también ha sido influenciado por artistas como Francis Bacon, M.C. Escher, J. L. Borges, Alan Parker, Ludwig Mies van der Rohe o Raymond Chandler (Herrero, 2015). 
cuyas temáticas son muy análogas en cuanto al género de ciencia ficción detectivesco, a la capacidad de entrar en los sueños ajenos y a los distintos niveles de realidad, creando un entramado laberíntico dentro del subconsciente.

Paprika es una adaptación de la novela homónima de Yasutaka Tsutsui (1993), e Inception parte de un guion original escrito por el propio Nolan. Del anime de Satoshi Kon actualmente no existe adaptación a videojuego. Respecto a la obra de Nolan, durante la rueda de prensa que ofreció en Roma por motivo del estreno de Inception (Vivarelli, 2010), el cineasta anunció que se estaba trabajando en un spin off del largometraje para ser trasladado exclusivamente a videojuego, pero desde entonces no ha habido más novedades al respecto.

Siguiendo esta línea de laberintos mentales, cabe destacar el caso de la trilogía The Matrix (1999), The Matrix Reloaded (2003) y The Matrix Revolutions (2003), de Lana y Lilly Wachowski, cuya historia se construye a un nivel transmedia ${ }^{18}$. Si sólo se consumen las películas, sólo se conoce una parte de la historia, por lo que los videojuegos enriquecen la propia obra cinematográfica, donde prevalecen el concepto del laberinto mental y los distintos niveles de realidad.

Otro ejemplo se encuentra en Donnie Darko (2001), película escrita y dirigida por Richard Kelly, en la que el protagonista tiene visiones de un conejo antropomorfo que predice el fin del mundo. En 2013, la película de Kelly tuvo un traslado a videojuego de 8 y 16 bits desarrollado por CineFix, que aunque no desarrolla el género laberíntico como tal, aborda los momentos más relevantes del largometraje (Rosenthal, 2014).

En la misma línea se encuentra Fight Club (1999), largometraje dirigido por David Fincher y adaptado de la novela homónima de Chuck Palahniuk (1996). La obra fue trasladada a videojuego por Genuine Games en 2004 para Xbox, PlayStation 2 y smartphones (Wolf, 2008). No obstante, la historia de Palahniuk afronta un conflicto intrapersonal cuyo laberinto mental es muy complejo, divergiendo de la adaptación al terreno del videojuego, que se centra en el género de lucha, obviando en gran medida la trama principal de la historia y adaptando únicamente una de sus tramas secundarias. En el caso de Inside Out (2015), largometraje de animación escrito y dirigido por Pete Docter y Ronnie del Carmen. Además de abordar el laberinto de las emociones a un nivel mental, la memoria a largo plazo se representa espacialmente como un laberinto de estanterías en las que se almacenan los recuerdos.

La adaptación de la obra de Pixar a videojuego fue desarrollada a través de Avalanche Software, estrenando un playset el mismo año del lanzamiento de la película, disponible principalmente para PlayStation 3, PlayStation 4, Xbox One, Wii U, Xbox 360, Android, y ordenadores (Otero, 2015). El videojuego cuenta una historia posterior a la de la obra cinematográfica en la que Riley, la niña protagonista, ha crecido. El jugador debe controlar sus emociones, por lo que el escenario en el que se transita es su propia mente, con una propuesta de adaptación que recae sobre el género de plataformas, aunque manteniendo el espíritu del laberinto mental y formal que se desarrolla en la obra cinematográfica.

También existen diversos títulos con simbología laberíntica a nivel espacial que han tenido adaptaciones en diferentes discursos, como es el caso de Alien vs. Predator (2004),

18 En el transmedia storytelling, la historia se expande a múltiples soportes. En el caso de The Matrix, además del anime y los cómics, existen varios videojuegos como Enter The Matrix (2003), desarrollado por Shiny Entertainment; The Matrix Online (2005), desarrollado por Monolith Productions; o The Matrix: Path of Neo (2005), desarrollado por Shiny Entertainment. 
película escrita y dirigida por el anteriormente citado Paul W. S. Anderson. El largometraje está irremediablemente influenciado por el videojuego homónimo que desarrolló Capcom en $1994^{19}$ (Wolf, 2008). El videojuego, cuya trama es de peleas callejeras, se aleja del largometraje de Anderson, en el que los seres humanos se encuentran atrapados en mitad de la lucha de los Aliens contra los Predators dentro de una pirámide que funciona como coto de caza. Sin embargo, la pirámide tiene vida propia y su estructura cambia constantemente, transformándose en un laberinto que separa a los personajes.

En 2010, Rebellion Software desarrolló la adaptación de la película de Anderson, que a su vez había estado inspirada en el videojuego de Capcom de 1994. El nuevo videojuego, disponible en Xbox 360, PlayStation 3 y ordenadores, lo distribuyó Sega, y abordaba el género shooter (como los anteriormente citados Doom y Battlefield), adaptando la esencia de la película de Anderson e incluyendo la pirámide como concepto laberíntico.

Otro título especialmente representativo es Labyrinth (1986), largometraje dirigido por Jim Henson y escrito por Terry Jones. En su trama, la joven Sarah Williams debe adentrarse en el interior de un laberinto para recuperar a su hermano pequeño, que ha sido raptado por Jareth, el rey de los goblins. Se hace uso de la simbología laberíntica como elemento iniciático y de madurez, además de un obstáculo espacial que se debe afrontar, siendo esta misma premisa la que se adaptó en el videojuego homónimo desarrollado por Lucasfilm Games el mismo año del estreno de la película, trasladando la misma historia en ambos soportes. Se trata de la primera aventura gráfica de Lucasfilm Games, y su repercusión fue tan notable que un año después desarrolló Maniac Mansion (1987), su segundo título (Donovan, 2010). Sin embargo, Labyrinth es una referencia moderna de su predecesora, la novela Alice's Adventures in Wonderland (1865), de Lewis Carroll. El laberinto surrealista que recorre Alicia en los dominios de la Reina de Corazones es un conocido elemento de la literatura fantástica que se ha trasladado al terreno cinematográfico (tanto en acción real como en animación) en varias ocasiones, siendo algunas de las adaptaciones más memorables las siguientes ${ }^{20}$ : Alice in Wonderland (1951), producida por Walt Disney; el musical británico Alice's Adventures in Wonderland (1972), dirigido por William Sterling; la truculenta Alice (1988), de Jan Švankmajer; o Alice in Wonderland (2010), dirigida por Tim Burton ${ }^{21}$.

En su adaptación a videojuego, al igual que sucede con el medio cinematográfico, existen diversos títulos que transitan en el universo de Carroll. Una de sus primeras adaptaciones, bajo el título Alice in Wonderland (1985), la desarrolló Dale Disharoon, disponible en Apple II y Commodore 64, aunque no actuaba en un formato de género laberíntico, sino de plataformas (Wolf, 2008). Sin embargo, se cuenta con adaptaciones en las que se desenvuelve la simbología laberíntica, como es el caso de Märchen Maze (1988), adaptación libre desarrollada por Nihon System, Namco y SPS; Alice in Wonderland (2000), desarrollada por Digital Eclipse y Left Field Productions para Game Boy Color; American McGee's Alice (2000), adaptación siniestra presentada por Rogue Entertainment para PlayStation 3, Xbox

19 Además de influencias como Alien (1979), de Ridley Scott (utilizando la nave espacial Nostromo como laberinto); Predator (1987), de John McTiernan (adaptando el laberinto a la selva); o los cómics de Dark Horse Comics.

20 Aparecen en el portal Teknoplof (2014), junto a más títulos que también adaptan la obra de Carroll.

21 Tim Burton también produjo Alice through the looking glass (2016), dirigida por James Bobin, en la que se tratan los viajes en el tiempo y la simbología del espejo, aunque no llega a adaptar Through the lookingglass, and what Alice found there (1871), la secuela escrita por Carroll. 
360 y ordenadores; o Alice in Wonderland (2010), adaptación de la película de Tim Burton desarrollada por Étranges Libellules para Nintendo DS, Wii, Zeebo y ordenadores ${ }^{22}$.

Las pruebas laberínticas están conectadas al hecho de superarse a uno mismo, de ahí que historias como Alice's Adventures in Wonderland o Labyrinth impliquen resolver acertijos, puzles y, en general, superar pruebas físicas o mentales de cualquier índole para cruzar un umbral o pasar de un escenario al siguiente. Esta característica está vinculada a los videojuegos, y convive en el terreno cinematográfico en sagas que, aunque no se centren solo en la simbología laberíntica, comparten intrínsecamente este factor de superación y han sido adaptadas a videojuegos, como sucede con Indiana Jones ${ }^{23}$ (personaje creado por George Lucas); The Maze Runner (basada en la trilogía homónima de James Dashner ${ }^{24}$ ); Harry Potter (basada en las novelas de J. K. Rowling ${ }^{25}$ ); o Saw, saga creada por James Wan y Leigh Whannell.

Un ejemplo diferente, en el que conviven cine y videojuegos, es el largometraje Tron (1982), escrito y dirigido por Steven Lisberger, cuya temática afronta el mundo de los videojuegos en sí mismo. La desarrolladora Bally Midway lo trasladó a videojuego el mismo año de su estreno cinematográfico, captando el espíritu del género laberíntico que aparece en la película. En el caso de The Shining (1980), largometraje dirigido por Stanley Kubrick basado en la novela homónima de Stephen King ${ }^{26}$ publicada en 1977, existe una adaptación a videojuego de 8 y 16 bits desarrollada por CineFix en 2013 (Méndez, 2013), pero no traslada la simbología laberíntica (mental y espacial) que se extiende y transfigura desde la mente del protagonista, el escritor Jack Torrance, a los laberínticos pasillos del hotel Overlook y, en último lugar, al laberinto botánico de setos que hay en el exterior de la localización, donde acaece una persecución visualmente propia de un videojuego de este género y que es fundamental en la propia trama junto a su clímax. No obstante, Picca Studio desarrolló The Shining Experience (2015) ${ }^{27}$, una obra que permite al espectador recorrer el hotel a través del punto de vista subjetivo del personaje de Danny Torrance montado en su triciclo, con una inmersión mayor gracias al Oculus Rift ${ }^{28}$, por lo que podría considerarse un híbrido, un videojuego de naturaleza cinematográfica.

\section{EL LABERINTO COMO GÉNERO}

Más allá de la simbología laberíntica a nivel mental, cuya frontera de definición daría lugar a encontrar infinidad de títulos, también existen numerosos casos en los que el laberinto se traslada a un nivel espacial. Se debe tener en cuenta que el concepto laberíntico en la industria de los videojuegos se plantea como un género en sí mismo ${ }^{29}$, pero en el terreno

22 En IGDB se encuentran estos títulos, además de otras adaptaciones y remakes de la obra de Carroll.

23 Saga dirigida por Steven Spielberg: Raiders of the Lost Ark (1981), Temple of Doom (1984), The Last Crusade (1989) y Kingdom of the Crystal Skull (2008).

24 La trilogía está siendo adaptada al medio cinematográfico por Wes Ball: The Maze Runner (2014), The Maze Runner: The Scorch Trials (2015) y The Maze Runner: The Death Cure (2018).

25 En particular, Harry Potter and the Goblet of Fire (2005), dirigida por Mike Newell.

26 También se encuentra disponible una serie de tres capítulos titulada Stephen King's The Shining (1997), dirigida por Mick Garris y con guión del propio Stephen King. Posteriormente, King escribió la secuela de The Shining bajo el título Doctor Sleep (2013), editada por Charles Scribner's Sons.

27 Disponible en WearVR (2015); <https://www.wearvr.com/apps/the-shining-experience> [consulta: 5 mayo 2017].

28 Casco de realidad virtual desarrollado por OculusVR.

29 En la industria del videojuego, el género laberíntico también se conoce popularmente como maze. 
cinematográfico implica únicamente una condición espacial o mental que conecta con la trama, pero no con un género como tal.

Dos de los primeros videojuegos de género laberíntico fueron Gotcha (1973), desarrollado por Atari, y Amazing Maze (1976), desarrollado por Midway (Wolf, 2008). En Gotcha, que fue el primer videojuego laberíntico que se comercializó, el jugador tenía que atrapar con una caja a un personaje representado por una equis dentro de un laberinto. A pesar de que Gotcha no tuvo el éxito esperado por parte de Atari, se podría considerar el precursor de Pac-Man, el videojuego laberíntico de perspectiva cenital por excelencia, desarrollado por Namco en 1980 (Wolf, 2008).

El género laberíntico en los videojuegos evolucionó desde entonces, y el laberinto como tal fue quedando relegado a un segundo nivel como elemento de obstáculo en la trama de algunos títulos, cuyo fin iba más allá del hecho de salir de aquel espacio, como fue el caso de Castle Wolfenstein (1981), desarrollado por Muse Software (Wolf, 2008), cuyo escenario principal era una serie de habitaciones laberínticas muy similares entre sí en un espacio monótono ${ }^{30}$, que con el paso del tiempo se trasladaría de la perspectiva cenital al punto de vista subjetivo en primera persona. En este aspecto, el género laberíntico ha ido progresando también en su propio lenguaje, traspasando la perspectiva cenital para hacer uso del punto de vista subjetivo (coexistente en el discurso cinematográfico como ya se ha comentado anteriormente), encontrando un elevado número de títulos, como es el caso de Súper Mario Bros, saga iniciada por Nintendo en 1985; Doom, saga desarrollada por Id Software y Nerve Software en 1993; o la saga Battlefield, desarrollada por EA Digital Illusions CE en 2002 (Wolf, 2008).

Cada vez resulta más complicado diferenciar el espacio en el que transcurre el videojuego del laberinto en sí mismo, ya que la simbología laberíntica está integrada con frecuencia en su discurso, siendo con regularidad un elemento más dentro de las dificultades a las que se deben enfrentar los jugadores. Además de los ya citados, existen multitud de títulos que contienen esta complejidad laberíntica a nivel espacial como un elemento más dentro de su trama, coexistiendo en muchos casos con géneros como las plataformas, los deportes o los RPG ${ }^{31}$. No sólo se trata de llegar al final, sino de saber cómo llegar, y este factor los conecta con la simbología laberíntica (Santarcangeli, 1997). Algunos ejemplos se encuentran en Navy Moves (1988), desarrollado por Dinamic Software; The Legend of Zelda (1986), saga desarrollada por Nintendo; Castlevania (1986), saga presentada por Konami; Sonic, the Hedgehog (1991)32, saga desarrollada por Sega con el laberinto siempre presente como elemento esencial; Mario Chase (2012) y Luigi's Ghost Mansion (2012), dos videojuegos incluidos en el pack Nintendo Land; Call of Duty (2003), saga que desarrolló inicialmente Infinity Ward; o Alone in the Dark (1992), saga presentada por Infogrames, tratándose de un survival horror que cuenta con varias secuelas y una adaptación cinematográfica homónima dirigida por Uwe Boll ${ }^{33}$, cuya premisa general es que el personaje debe explorar una mansión además de encontrar la salida, un hecho correspondiente a la simbología laberíntica.

En esta misma línea, existen diversos títulos (o sagas) de videojuegos que, en determinados momentos de la trama adquieren una componente laberíntica que, con mayor

30 Elemento característico de la simbología laberíntica.

31 RPG: videojuegos de rol (Role-Playing Games).

32 Según IMDb, en 2018 se estrenará la adaptación cinematográfica de Sonic, the Hedgehog con el largometraje homónimo dirigido por Jeff Fowler.

33 Estrenada en 2005, siendo una continuación de la trama del videojuego Alone in the Dark: The New Nightmare (2001), desarrollado por Infogrames. 
o menor éxito, ha sido trasladada al discurso cinematográfico, como es el caso de Prince of Persia: The Sands of Time (2003), desarrollado por Ubisoft Montrea ${ }^{34}$, que fue adaptado al cine por Mike Newell en 2010. Otros ejemplos son Silent Hill (1999), saga desarrollada originariamente por Konami y trasladada al cine por Christophe Gans en 2006; Resident Evil (1996), saga presentada por Capcom y trasladada al cine por Paul W. S. Anderson en Resident Evil (2002), Resident Evil: Afterlife (2010), Resident Evil: Retribution (2012) y Resident Evil: The Final Chapter (2017); o Lara Croft: Tomb Raider, saga iniciada por Core Design en 1996, que fue trasladada al cine en Lara Croft: Tomb Raider (2001), dirigida por Simon West, y Lara Croft Tomb Raider: The Cradle of Life (2003), dirigida por Jan de Bont, tratándose de un ejemplo de viabilidad económica a la hora de trasladar un videojuego al formato cinematográfico (Martínez, 2016: 14-18).

\section{CINE LABERÍNTICO SIN ADAPTACIÓN A VIDEOJUEGO}

La industria cinematográfica ha concebido títulos que, a pesar de su simbología laberíntica a nivel espacial, no han tenido adaptación a videojuegos. Uno de los casos es la película Playtime (1967), escrita y dirigida por el cineasta francés Jacques Tati, en la que aparece su popular personaje Monsieur Hulot ${ }^{35}$, el cual se enfrenta al mundo moderno en espacios llenos de frialdad que son tan repetitivos que al final termina perdiéndose entre sus recodos, como si de un laberinto moderno se tratara. Otros ejemplos los encontramos en Satyricón (1969), escrita y dirigida por Federico Fellini, mostrando un laberinto con una vertiente más existencialista; Orlando (1992), dirigida por Sally Potter, basada en la novela homónima de Virginia Woolf (1928); Stay Tuned (1992), dirigida por Peter Hyams y escrita por Tom S. Parker y Jim Jennewein, con la televisión como un laberinto del que hay que salir; Sleuth (1972), dirigida por Joseph L. Mankiewicz y escrita por Anthony Shaffer, siendo un thriller psicológico que se inicia con el espacio laberíntico; Apocalypse Now (1979), dirigida por Francis Ford Coppola, adaptando la novela Heart of Darkness (1899), de Joseph Conrad, con el río como laberinto y el coronel Kurtz como Minotauro, tratándose de una historia que Coppola desea adaptar a videojuego (Cejas, 2017); Cube (1998), escrita y dirigida por Vincenzo Natali; Dark City (1998), escrita y dirigida por Alex Proyas, con la presencia de laberintos circulares; Symbol (2009), escrita y dirigida por Hitoshi Matsumoto, con similitudes a Cube, pero en una única habitación; La habitación de Fermat (2007), escrita y dirigida por Luis Piedrahita y Rodrigo Sopeña, también en la línea de Cube; o El laberinto del fauno (2006), largometraje escrito y dirigido por Guillermo del Toro. Este último posee, entre su multitud de referencias, ese espíritu de superación, madurez y pruebas que Ofelia, la niña protagonista, debe superar. Se hace uso del laberinto como un elemento simbólico a modo de refugio de la cruda realidad, tras finalizar la Guerra Civil española, que envuelve a la película. Sin embargo, tampoco existe una adaptación relevante a videojuego, solo una versión en 8 y 16 bits de plataformas desarrollada por CineFix en 2015 (Rodgers, 2015). En ella se traslada la misma trama y las pruebas que Ofelia debe superar, pero sin hacerse demasiado eco de la simbología laberíntica de la obra cinematográfica, que adopta el arquetipo del laberinto como elemento iniciático y de madurez.

34 Aunque su primera versión la realizó Jordan Mechner en 1989 para Apple II.

35 Jacques Tati mostró a Monsieur Hulot, personaje que él mismo interpretó, en Les vacances de Monsieur Hulot (1953), Mon oncle (1959), Playtime (1967) y Trafic (1971). 
Existen otros ejemplos de películas de especial relevancia histórica o temática que abordan la simbología laberíntica a un nivel mental, aunque en la actualidad carecen de adaptación en la industria del videojuego. Algunas de ellas son The Lady from Shanghai (1947), dirigida por Orson Welles y adaptada de la novela If I die before I wake (1938), de Sherwood King, cuya simbología laberíntica mental se traslada al final del metraje con la memorable escena del laberinto de espejos; L'annèe dernière à Marienbad (1961), dirigida por Alain Resnais y adaptada de la novela La invención de Morel (1940), de Bioy Casares, siendo una historia que transcurre en la compleja y laberíntica mente de los personajes ${ }^{36}$; Persona (1966), escrita y dirigida por Ingmar Bergman, afrontando los sueños y la complejidad del ser humano a través de la mirada del cineasta sueco; Twelve Monkeys (1995) ${ }^{37}$, dirigida por Terry Gilliam e inspirada en el cortometraje La Jetée (1962), de Chris Marker, con una historia emplazada en un futuro distópico; Being John Malkovich (1999), dirigida por Spike Jonze y escrita por Charlie Kaufman, con la presencia de un túnel que conduce literalmente a la mente del actor John Malkovich; El corazón del guerrero (2000), escrita y dirigida por Daniel Monzón, con una trama adherida a los juegos de rol; The Cell (2000), dirigida por Tarsem Singh y escrita por Mark Protosevich, cuya protagonista es una psicoterapeuta que se introduce en la mente de sus pacientes; Split (2016), escrita y dirigida por M. Night Shyamalan, con una trama de multipersonalidad influenciada por Psycho; o los laberintos desestructurados (a nivel mental y en ocasiones formal) de la filmografía de David Lynch, sobre todo con Lost Highway (1997), Mulholland Drive (2001), e Inland Empire (2006).

\section{EL CASO DE BASKERVILLE}

Umberto Eco diferenció tres tipos de laberintos: el clásico, el manierista y en forma de red. El laberinto clásico (o unilineal) es aquel que se llega hasta el centro y posteriormente se regresa al punto inicial. En el caso del laberinto manierista, su estructura estaría formada por un elevado número de callejones y recovecos teniendo que decidir qué dirección tomar. Es decir, no se regresaría al punto inicial como en el caso del laberinto clásico. En último lugar, Eco define al laberinto en forma de red como un espacio sin centro ni salida en el que cada pasadizo puede estar en conexión con el resto, tratándose de un lugar sin límites, activándose los principios de conexión, multiplicidad, metamorfosis y espacio infinito (Eco, 1987: 18-27).

La tipología espacial de Umberto Eco se traslada también a un estado mental, conectando los niveles de complejidad del ser humano a sus propios laberintos intrínsecos. En consecuencia, la simbología laberíntica juega un papel determinante en la obra de Eco, especialmente en su novela de ficción II nome della rosa (1980). En ella, el autor narra una historia de género policíaco o detectivesco ${ }^{38}$ al estilo de Ten Little Niggers ${ }^{39}$ (Christie, 1939),

36 Dos de las primeras películas con referencias borgianas directas son la citada L'annèe dernière à Marienbad (1961) y Paris nous appartient (1961), de Jaques Rivette, en cuyo inicio aparece un ejemplar de Otras inquisiciones, ensayo de J. L. Borges publicado en 1952.

37 En 2015, Syfy estrenó una serie homónima basada en la adaptación de Gilliam.

38 La novela se construye en torno a una serie de crímenes, y los personajes de fray Guillermo de Baskerville y Adso de Melk rememoran a Sherlok Holmes y al Dr. Watson (este último recuerda fonéticamente al nombre de Adso), personajes creados por Arthur Conan Doyle que participaron juntos en varias historias, siendo una de ellas The Hound of the Baskervilles (1902), cuyo título también se homenajea en la novela de Eco.

39 La novela policíaca de Agatha Christie (trasladada al cine en varias ocasiones) también trata de una serie de crímenes que van sucediéndose uno tras otro sin saber quién es el asesino. 
pero ambientada en la Baja Edad Media. La trama está circunscrita a una abadía benedictina de un indeterminado lugar del norte de Italia en la que acaecen varios asesinatos vinculados a la existencia del segundo libro de Poética de Aristóteles, dedicado a la comedia. Dentro de la abadía se encuentra una biblioteca borgiana ${ }^{40}$, cuyo plano recuerda al laberinto de la Catedral de Reims (Fig. 1), grabado que influyó en Eco a la hora de diseñarla y ubicarla en el interior de una elevada torre octogonal (Fig. 2). Eco la ideó como un gran laberinto clásico, siendo una metáfora del mundo y de la propia cultura.

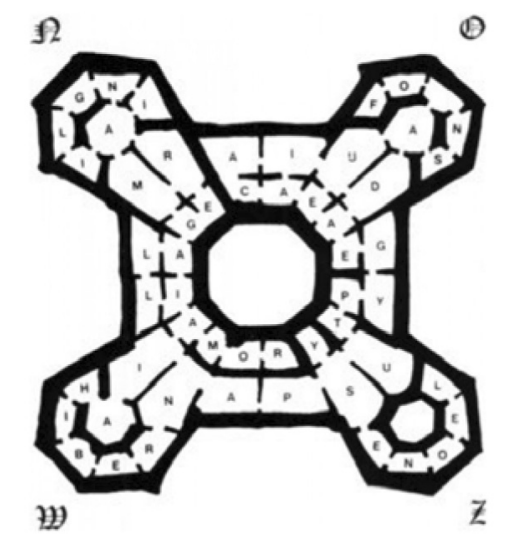

Figura 2: Plano de la biblioteca de II nome della rosa (Eco, 1980).

Fuente: <http://www.architecturalpapers.ch/index.php?ID=75>

[consulta: 5 mayo 2017].

El fraile franciscano Guillermo de Baskerville y el novicio Adso de Melk se pierden en el interior de la biblioteca, ya que el lugar está formado por un conglomerado de escaleras de diferentes alturas muy similares entre sí que recuerdan a las Carceri $d^{\prime \prime I n v e n z i o n e}{ }^{41}$ (Fig. 3), una serie de grabados realizados por Giovanni Piranesi de 1745 a 1750 (Focillon, 1918), los cuales influenciarían posteriormente a M.C. Escher y a J. L. Borges. Los universos imposibles de Escher y los mundos de Borges asentarían una elevada influencia en cineastas como Christopher Nolan (Herrero, 2015). No obstante, Piranesi es uno de los detonantes principales en cuanto al desarrollo e influencia posterior de los laberintos de complejas escalinatas y estructuras ${ }^{42}$.

La novela de Eco contiene un elevado número símbolos ${ }^{43}$, y en el interior del laberinto, el hilo de Ariadna ${ }^{44}$ se simbolizaría a través del tejido de las vestimentas que Adso (como un

40 Muchos de los cuentos de J. L. Borges, como La biblioteca de Babel, incluido en la antología Ficciones (1944), han influido en la totalidad de la obra de Eco.

41 Las Carceri d'Invenzione son 16 grabados de cárceles imaginarias cuyas perspectivas no tienen lógica en diédrico, lo cual influiría posteriormente en el estilo de M. C. Escher, por ejemplo, con la escalera infinita de Penrose, que también utilizaría Christopher Nolan en Inception (2010).

42 Dante Alighieri (1265-1321) describió el Infierno de su Divina Comedia con la forma de nueve círculos de complejas estructuras que se introducían en el subsuelo, lo cual sugiere cierta influencia posterior en Piranesi. Y Gustave Doré (1832-1883) se encargó de ilustrar la obra de Dante siglos después, cuyas imágenes recuerdan a las Carceri d'Invenzione de Piranesi.

43 El espejo, por ejemplo, simboliza la dualidad, la imaginación y el mundo de las emociones, y también está presente en la biblioteca, asustando a Adso de Melk al verse reflejado en él de manera distorsionada. El espejo es un elemento que se repite constantemente con este carácter simbólico, como sucede en largometrajes como los anteriormente citados Labyrinth (1986), de Jim Henson; o Alice through the looking glass (2016), de James Bobin.

44 En la mitología griega, Ariadna le regaló a Teseo un ovillo para que, una vez dentro del laberinto construido por Dédalo, fuera desenrollándolo y pudiera servirle de guía, indicándole el camino de regreso tras acabar con la vida del Minotauro (Graves, 1988). 


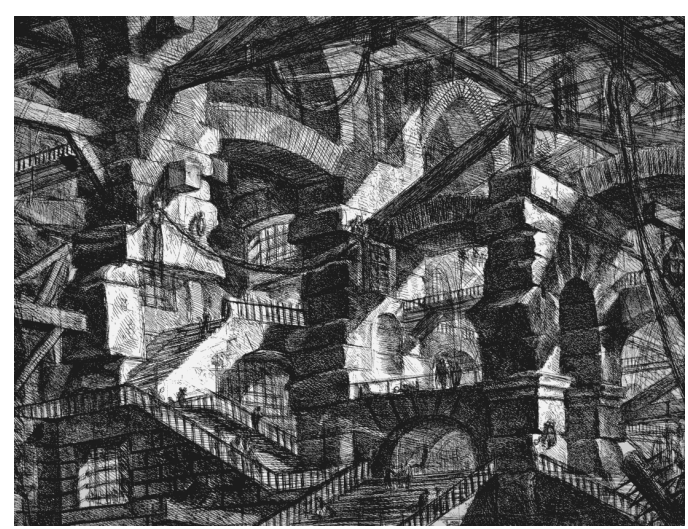

Figura 3: Grabado XIV de las Carceri d'Invenzione (Piranesi, 1745-1750). Fuente: <http://www.italianways.com/le-carceri-dinvenzione-di-piranesi/> [consulta: 5 mayo 2017].

Teseo medieval) va dejando caer tras de sí para saber regresar al punto inicial; y la analogía con el Minotauro vendría dada a través del personaje de Jorge de Burgos, el monje ciego que aguarda en el interior de la biblioteca. El cineasta francés Jean-Jacques Annaud adaptó la novela de Umberto Eco al medio cinematográfico (en co-producción entre Italia, Francia y Alemania) bajo el título original Der Name der Rose (1986). En la adaptación, con los códigos propios del cine (que difieren de la literatura a la hora de adaptar cualquier obra), Annaud acentúa los momentos de mayor acción de la novela, haciendo hincapié en la trama en torno a los crímenes de la abadía. Sin embargo, parte de las subtramas que se entrecruzan - que derivan a raíz de los asesinatos y las suposiciones que realiza fray Guillermo de Baskerville quedan en un segundo plano o no aparecen (laberintos mentales manieristas y en forma de red), enfatizando otros aspectos como la relación de Adso de Melk con la joven campesina de nombre desconocido ${ }^{45}$ que se encuentra escondida en la cocina de la abadía. Se trata de un momento fugaz en la novela que en la adaptación cinematográfica incide como otro eje temático clave. No obstante, aunque Annaud se centra más en la trama detectivesca y amorosa que en los entresijos filosóficos de la obra literaria, cabe destacar que la reproducción de la biblioteca, rememorando los grabados de Piranesi, es notable. Adapta con relativa fidelidad ese espíritu laberíntico a nivel espacial (Fig. 4).

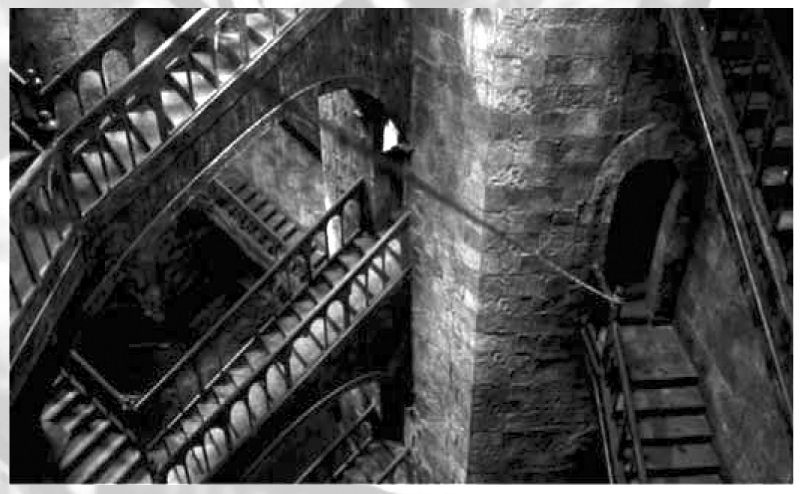

Figura 4: Fotograma de Der Name der Rose (Jean-Jacques Annaud, 1986).

Fuente: <https://laminmin.wordpress.com/2010/08/25/tiempo-87/nombredelarosa3/> [consulta: 5 mayo 2017].

45 Annaud vincula el desconocimiento del nombre de la campesina con el título de la película, mientras que en la novela no están necesariamente relacionados, convergiendo más con el nominalismo y el empirismo de Guillermo de Ockham, el alter ego de Guillermo de Baskerville (Gilson, 1972). 
En 1987, un año después del estreno de la adaptación cinematográfica, la popular desarrolladora española Opera Soft solicitó los derechos a Umberto Eco para poder trasladar a videojuego su novela, sobre todo a raíz del éxito obtenido, tanto de la novela como de la película (Esteve, 2012). Los programadores Paco Menéndez y Juan Delcán, impulsores y desarrolladores del proyecto, no tuvieron una respuesta positiva por parte de Eco, así que sacaron adelante la adaptación de manera no oficial y bajo el título La abadía del crimen (uno de los títulos que Eco había barajado para su novela). El videojuego, en formato de 8 y 16 bits, salió a la venta para Amstrad CPC, Spectrum, MSX y PC ${ }^{46}$, pero no tuvo el éxito comercial esperado (Esteve, 2012).

No obstante, La abadía del crimen terminó convirtiéndose en un título de culto, adaptando con cierto rigor la novela y dando lugar a la publicación de otro libro ${ }^{47}$. Los personajes principales de la adaptación al videojuego también eran Guillermo de Baskerville y Adso de Melk, aunque los nombres no eran exactamente iguales. En la novela, Eco contaba su historia a través de los ojos del joven Adso, siendo el verdadero protagonista. Sin embargo, el protagonismo del videojuego se trasladó a Guillermo de Baskerville, que adoptó el nombre de Guillermo de $\mathrm{Occam}^{48}$. No obstante, en determinados momentos del videojuego el jugador también utilizaba el personaje de Adso, que había perdido su apellido pero mantenía su rol de joven novicio. Siguiendo la misma trama detectivesca de la novela, en el videojuego había que averiguar quién era el responsable de los asesinatos que estaban sucediendo en la abadía a través de una historia desarrollada durante siete días en los que el jugador adoptaba los roles propios de un monje medieval, debiendo cumplir con sus obligaciones pertinentes (como obedecer al abad o asistir a misa), además de investigar los crímenes, siendo motivo de expulsión de la abadía el hecho de no cumplir con alguna de las labores. Estos factores convirtieron al videojuego en una obra especialmente compleja, sobre todo por el paradigma laberíntico que tanto había influenciado a Eco por parte de Piranesi, Escher y Borges ${ }^{49}$, que posteriormente adaptaría Annaud en su versión cinematográfica, y que se trasladaría a continuación a esta versión no oficial del videojuego que se realizó en España. En el escenario del videojuego, las pantallas que iban apareciendo al cambiar de espacio también modificaban su perspectiva, y esto generaba cierta desorientación en el jugador, siendo a veces muy acentuada en el laberinto de la biblioteca, sobre todo cuando los personajes enarbolaban un candil mientras caminaban, viéndose el resto de la estancia en oscuridad. El videojuego ha tenido varios remakes posteriores, como el que realizó el programador Antonio Giner González en 1999, que adaptó el videojuego original de 1987 pero con música remasterizada, 256 colores, y compatible con los soportes actuales. Otros casos son The Abbey (2008), aventura gráfica que desarrolló Alcachofa Soft, siendo una adaptación libre de la novela de Eco en la que el personaje de fray Leonardo de Toledo y el novicio Bruno investigan una serie de crímenes en una abadía española (Hernández, 2009);

46 Disponible en La abadía del crimen (1999); <http://www.abadiadelcrimen.com/> [última consulta: 05/05/2017].

47 Esteve, Jaume, Obsequium: un relato cultural, tecnológico y emocional de La abadía del crimen, Barcelona, Ocho Quilates, 2014.

48 Guillermo de Ockham (1285-1349) también aparece a menudo escrito como Guillermo de Occam, y fue un filósofo conectado al empirismo y al nominalismo (Gilson, 1972) del que ya se ha citado su relación de alter ego con Guillermo de Baskerville.

49 Incluyendo otras referencias, como la Divina Comedia de Dante ilustrada por Doré. 
- La abadía del crimen Extensum (2014)50, otro remake de la edición de 1987 desarrollado por los programadores Manuel Pazos y Daniel Celemín (Fig. 5) (Esteve, 2012).

En consecuencia, la novela de Eco es un caso superlativo de simbología, adaptación e influencias laberínticas, tanto a nivel mental en su trama detectivesca (y subtramas), como espacial en la propia biblioteca51. Esta esencia se ha mantenido, en mayor o menor medida, en su traslado a la pantalla cinematográfica y a la industria de los videojuegos, todos ellos realizados en España salvo alguna excepción, como /I Noma della Rosa $(1993)^{52}$, que se desarrolló en Eslovaquia a través Perpetum, disponible para ZX Spectrum 48K. El caso de Baskerville es un ejemplo singular en el que el traslado de la simbología laberíntica se prolonga de manera muy acentuada en el tiempo: desde el laberinto de la Catedral de Reims, la Divina Comedia de Dante y las Carceri d'Invenzione de Piranesi a Jean-Jacques Annaud, pasando por Escher, Borges, Eco, y llegando finalmente al videojuego español La abadía del crimen, junto a sus remakes y adaptaciones posteriores.

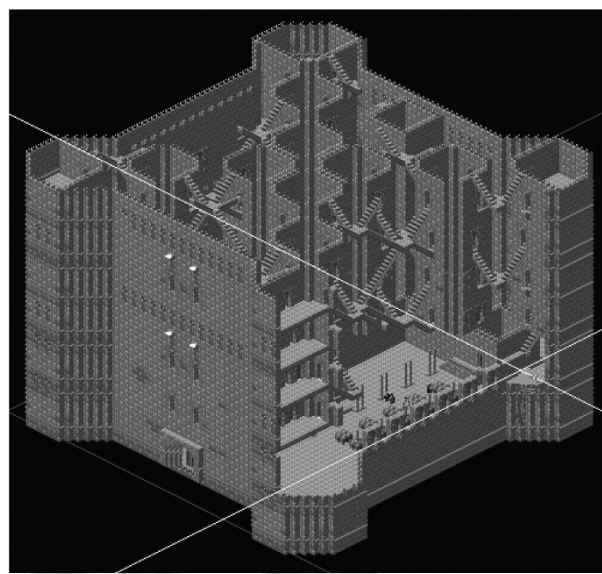

Figura 5: Diseño de la biblioteca en La abadía del crimen Extensum. (Pazos y Celemín, 2014).

Fuente: <http://www.retroworks.es/php/retroblog.php?tag=17>

\section{CONCLUSIÓN} [consulta: 5 mayo 2017].

La simbología laberíntica ha formado parte de la industria cinematográfica y del videojuego prácticamente desde la invención de ambos medios, ya que es un recurso heredado del resto de artes, con especial hincapié en la pintura, la arquitectura y la literatura. El laberinto es un paradigma inexorablemente arraigado en la sociedad por ser uno de sus símbolos más antiguos, y se traslada convirtiéndose en un intrincado y desafiante lugar que motiva al movimiento, a esa pérdida de estatismo para lograr un objetivo, superando niveles y creciendo en ese camino iniciático y de madurez que conecta a los valores más profundos del ser humano.

El citado camino se adapta al cine y a los videojuegos conectando irremediablemente con los espectadores y los jugadores en ese afán de superación, resolución de problemas y cumplimiento del objetivo final.

50 Disponible en La abadía del crimen Extensum (2014); <http://www.abadiadelcrimenextensum.com/> [última consulta: 05/05/2017].

51 Y a diferentes niveles de dificultad, como se propone en la tipología laberíntica de Eco.

52 Disponible en World ofSpectrum (2011); <http://www.worldofspectrum.org/infoseekid.cgi?id=0015662> [consulta: 5 mayo 2017]. 
En el presente texto se han dado a conocer de forma introductoria algunos de los títulos más representativos del terreno cinematográfico y de la industria del videojuego que, en mayor o menor medida, se encuentran dentro de los parámetros laberínticos, bien sea a un nivel mental, espacial o ambos.

Los ejemplos comentados dan buena cuenta de cómo el género laberíntico forma parte de los videojuegos de tal modo que funciona como un género en sí mismo, siendo parte de la cultura colectiva que ha traspasado el formato, coexistiendo con un medio audiovisual en el que las convergencias y divergencias en ocasiones comparten una frontera que se diluye con los avances tecnológicos y la proliferación del cine interactivo.

¿Puede entonces la simbología laberíntica mantenerse o evolucionar en la industria cultural? De momento, las influencias en los discursos están presentes y han evolucionado con gran evidencia, teniendo el paradigmático ejemplo de II nome della rosa, cuyas influencias, adaptaciones y posible evolución futura requeriría de un análisis más pormenorizado.

La simbología laberíntica está tan arraigada socialmente que en la industria del videojuego es un género cuya complejidad evoluciona y convive con otros elementos. Por otro lado, los nuevos soportes acercan la interactividad del jugador al medio cinematográfico a través de la inmersión en ese intrincado espacio. Por lo tanto, el camino evolutivo de la simbología laberíntica termina siendo un laberinto en sí mismo. Un laberinto en el que el espectador y el jugador se fusionan en una única persona con el deseo de alcanzar el objetivo final.

\section{BIBLIOGRAFÍA CITADA}

AGUDO, Sergio, Gates Motel, el videojuego tributo a Psicosis de Hitchcock, Valencia, Malavida, 2016; <http://www.malavida.com/es/noticias/gates-motel-el-videojuegotributo-a-psicosis-de-hitchcock-006083\#gref> [consulta: 5 mayo 2017].

BONITZER, Pascal, «Partial Vision: Film and the Labyrinth», Baltimore, Johns Hopkins University Press, Wide Angle 4 (1981), pp. 56-63.

CASTLE, William, Step Right Up! I'm gonna scare the pants off America: Memoirs of a BMovie Mogul, Nueva York, Putnam, 1976.

CEJAS, Sergio, El videojuego de Apocalypse Now abandona Kickstarter e inicia su propia plataforma de crowdfunding, Madrid, Vida Extra, 2017; <https://www.vidaextra.com/fps/ el-videojuego-de-apocalypse-now-abandona-kickstarter-e-inicia-su-propia-plataformade-crowdfunding $>$ [consulta: 5 mayo 2017].

DE COVARRUBIAS, Sebastián [1611], ed. Martín de Riquer, Tesoro de la lengua castellana o española, Madrid, Horta, 1943:746.

DONOVAN, Tristan, Replay: The History of video games, Reino Unido, Yellow Ant Media Ltd., 2010.

ECO, Umberto, «La línea y el laberinto: las estructuras del pensamiento latino», Revista Vuelta IX (1987), pp.18-27.

ECO, Umberto, Il nome della rosa, Milán, Bompiani, 1980.

ESTEVE, Jaume, Obsequium: un relato cultural, tecnológico y emocional de La abadía del crimen, Barcelona, Ocho Quilates, 2014.

ESTEVE, Jaume, Una historia de la Edad de Oro del software español (1987-1992), Barcelona, Ocho Quilates, 2012.

FOCILLON, Henri, Giovanni Battista Piranesi, París, Laurens, 1918. 
FREIRE, Héctor, El cine como laberinto, Buenos Aires, Topia, 2009; <https://www.topia.com. ar/articulos/cine-como-laberinto> [consulta: 5 mayo 2017].

GILSON, Etienne, La filosofía en la Edad Media, Madrid, Gredos, 1972.

GINSER, Nick, Memento, Irlanda, Untold Gaming, 2016; <http://untoldgaming.com/labogame-studio-releases-memento-on-steam/> [consulta: 5 mayo 2017].

GRAVES, Robert, Mitos griegos, Madrid, Alianza Editorial, 1988.

HERNÁNDEZ, José Román, The Abbey (La abadía), Santa Cruz de Tenerife, Emezeta, 2009; $<$ https://www.emezeta.com/articulos/the-abbey-la-abadia> [consulta: 5 mayo 2017].

HERRERO HERRERO, Miguel, Hiperficción, Sax, Cinestesia, 2015.

MANS, Claudi, Influencias mutuas entre Dante, Borges, Eco, Piranesi, Escher y Annaud, Barcelona, Investigación y Ciencia, 2013; <http://www.investigacionyciencia.es/blogs/ fisica-y-quimica/24/posts/el-arte-cientfico-que-me-gusta-7-piranesi-10805> [consulta: 5 mayo 2017].

MARTÍNEZ, Mario-Paul, "Trasladar la partida: Modelos y estrategias de la industria cinematográfica frente a la adaptación de un videojuego», Miguel Hernández Communication Journal (2016), pp. 14-18.

MÉNDEZ, Manuel Ángel, La mejor versión de El Resplandor: en videojuego de 8-bits, Gizmodo Media Group, LLC., 2013; <http://es.gizmodo.com/la-mejor-version-de-elresplandor-en-videojuego-de-8-b-1447662553> [consulta: 5 mayo 2017].

OTERO, César, Disney Infinity 3.0: Inside Out, el toque Mario con estilo Pixar, Madrid, MeriStation, 2015; <http://www.meristation.com/noticias/disney-infinity-3-0-inside-outel-toque-mario-con-estilo-pixar/2064222> [consulta: 5 mayo 2017].

PECKHAM, James, Hardcore Henry: how the first ever first-person action movie was made, Reino Unido, Techradar, 2016; <http://www.techradar.com/news/home-cinema/hardcorehenry-how-the-first-ever-first-person-action-movie-was-made-1318309> [consulta: 5 mayo 2017].

PRÉSTAMO, Jonathan, Evolución cinematográfica de la Alicia de Lewis Carroll desde 1903 hasta 2013, País Vasco, Teknoplof, 2014; <http://www.teknoplof.com/2014/03/06/ evolucion-cinematografica-de-la-alicia-de-lewis-carroll-desde-1903-hasta-2013/> [consulta: 5 mayo 2017].

RODGERS, Blake, The 8-bit cinema of Pan's Labyrinth is still beautiful and just as creepy, Nerdist, 2015; <http://nerdist.com/the-8-bit-cinema-of-pans-labyrinth-is-still-beautifuland-just-as-creepy/> [consulta: 5 mayo 2017].

ROSENTHAL, Emerson, Nueva adaptación de Donnie Darko en 8 bits (y un poquito de 16 bits), Creators, 2014; <https://creators.vice.com/es/article/nueva-adaptacion-dedonnie-darko-en-8-bits-y-un-poquito-de-16-bits> [consulta: 5 mayo 2017].

SANTARCANGELI, Paolo, El libro de los laberintos. Historia de un mito y de un símbolo, Madrid, Siruela, 1997.

TRUFFAUT, François, El cine según Hitchcock, Madrid, Alianza, 1974: 138.

VIVARELLI, Nick, Nolan: Video game may be in the works, Nueva York, Variey, 2010; <http:// variety.com/2010/film/box-office/inception-grosses-753-mil-worldwide-1118024429/> [consulta: 5 mayo 2017].

WOLF, Mark, The video game explosion: A history from Pong to Playstation and beyond, Connecticut, Greenwood Press, 2009. 